\title{
Simulation-Based Otorhinolaryngology Emergencies Boot Camp: Part 1: Curriculum Design and Airway Skills
}

\author{
Kelly M. Malloy, MD, FACS; Sonya Malekzadeh, MD, FACS; Ellen S. Deutsch, MD, FACS
}

Key Words: Simulation, boot camp, resident education, cricothyrotomy, laryngoscopy, bronchoscopy, epistaxis, emergency, medical education, surgical education.

Laryngoscope, 124:1562-1565, 2014

\section{INTRODUCTION}

Simulation-based boot camps provide novice trainees with an accelerated introduction to the essential skills needed for successful clinical management and professional development in a format that is valued by both residents and faculty. ${ }^{1,2}$ Boot camps have been described in numerous surgical and medical disciplines, including pediatrics, obstetrics and gynecology, orthopedics, cardiothoracic, and general and neurosurgery. ${ }^{3-9}$ Based loosely on the concept of military boot camps, residents actively participate in a concentrated variety of exercises designed to develop basic competence in relevant psychomotor, cognitive, and affective skills. Simulationbased boot camps are generally 1 to 3 days long, and the curriculum is designed to provide hands-on experience learning skills of increasing complexity. ${ }^{1}$ Boot camps are of particular value in smaller specialties like otolaryngology. Although each residency program has a relatively small number of residents at any given postgraduate year (PGY) level, boot camps enroll multiple learners from various institutions at similar PGY levels. Faculty can exchange ideas and teaching techniques as well as take

From the Department of Otolaryngology-Head and Neck Surgery (к.м.м.), University of Michigan Health System, Ann Arbor, Michigan; Department of Otolaryngology-Head and Neck Surgery (s.m.), MedStar Georgetown University Hospital, Washington, DC; and Department of Anesthesia and Critical Care (E.s.D.), The Children's Hospital of Philadelphia, Philadelphia, Pennsylvania, U.S.A.

Additional Supporting Information may be found in the online version of this article.

Editor's Note: This Manuscript was accepted for publication November 13, 2013.

The course was conducted at Simulation \& Training Environment Laboratory and MedStar Georgetown University Hospital.

The authors have no funding, financial relationships, or conflicts of interest to disclose.

Send correspondence to Kelly M. Malloy, MD, Department of Otolaryngology-Head and Neck Surgery, University of Michigan Health System, 1500 E. Medical Center Drive, First Floor, Taubman Center, Ann Arbor, MI 48109. E-mail: kellymal@umich.edu

DOI: 10.1002/lary.24572 advantage of simulation-based medical education not necessarily available at their own institution.

This purpose of this article, the first in a series of three, is to describe the first Otorhinolaryngology (ORL) Emergencies Boot Camp curriculum design and basic airway skills stations; subsequent articles will detail the remaining elements of the course curriculum, allowing other institutions to implement this curriculum and/or develop their own simulation-based curricula. To accomplish psychological safety, formal objective evaluations are not conducted during the boot camps. However, formal evaluations of the boot camp programs by both residents and faculty demonstrate high levels of satisfaction and are used for programmatic improvement. ${ }^{1,2}$

\section{CURRICULUM DESIGN}

For the ORL Emergencies Boot Camp, we defined our learner as the novice ORL resident. A needs assessment was performed that included a precourse survey of participating residents, predominantly PGY-2s, who expressed concerns about complex airway management, particularly emergent surgical airway control, and the management of all types of hemorrhage (e.g., epistaxis, postsurgical neck hematoma). ${ }^{1}$ Otolaryngology faculty reinforced the need for knowledge and skills to manage these basic ORL emergencies. The overarching "terminal" objectives for the ORL Emergencies Boot Camp were that the learners should be able to: 1) recognize and triage typical ORL emergencies, 2) perform basic emergency management skills, and 3) communicate effectively with the team. Based on course objectives, a variety of diverse instructional methods are utilized, emphasizing critical thinking and problem solving consistent with adult learning principles. The instructional methods were selected to maximize effective teaching and learning to achieve the learning objectives.

Participatory objectives for each skill station or session emphasize the specific action that the learner should be able to "do." Objectives are built with an 
action, a subject, and a metric such as "create and place (action) a (metric: one) posterior nasal pack (subject)." Objectives are clear, active, and whenever possible, measurable. Concise one-page informational handouts guide faculty and learners at each station, containing the learning objectives and other important considerations about patient assessment, necessary equipment, procedure details, and pearls of wisdom.

\section{BOOT CAMP FORMAT}

Following an orientation and recognizing that previous experience with basic airway management varies between residents, the ORL Emergencies Boot Camp starts with basic "calisthenics," simpler tasks upon which participants will later build more advanced skills. Performing basic airway skills like mask ventilation and intubation introduces or refamiliarizes participants with basic techniques and familiarizes them with the manikins and airway equipment. Once basic skills are reviewed and mastered, the boot camp moves on to "special skills" that are more challenging and less familiar, such as operative endoscopy, cricothyroidotomy, and control of epistaxis. Increasingly complex skills are introduced sequentially. No lectures are given; instead, hands-on practice time is optimized. A brief faculty demonstration is valuable in allowing learners to observe each other as they practice. Finally, in the latter part of the boot camp, these new skills are combined and used to manage complex clinical scenarios in which participants must work together as a team to manage a sick "patient" (a high-technology manikin) with an airway complication.

To present ORL emergency scenarios that are difficult to demonstrate realistically using simulation, there is a session that uses PowerPoint (Microsoft Corp., Redmond, WA) images and an audience response system (ARS) titled "It's $3 \mathrm{AM}$, do I really need to call my attending?" The residents are presented with information that they might receive during a phone call or a consultation, and they must determine whether certain conditions are truly emergencies, what additional information is required, what intervention is appropriate, and what would be a reasonable time frame for managing this condition. Learners use the ARS to anonymously select responses; the tallied group results are immediately visible, and a faculty panel leads a discussion regarding appropriate care for each case.

Designing the boot camp schedule depends upon the number of participants, simulators, space, and faculty. We provide an example of our schedule for 36 participants to illustrate how the skills are presented in a graduated fashion from simple to complex (Supplementary Information 1) and how duplicate identical stations are used to minimize the number of residents at each station and maximize each individuals' hands-on time (Fig. 1).

\section{SKILLS STATIONS-BASIC AIRWAY MANAGEMENT AND FIBEROPTIC INTUBATION}

The design of each of the skills stations is described below, with information addressing the educational premise, the handout for participants, recommended simulators, a description and checklist for additional equipment and supplies needed for the simulation, station setup, and an illustrative photograph. Handouts for each station are succinct summaries, limited to one page, which include

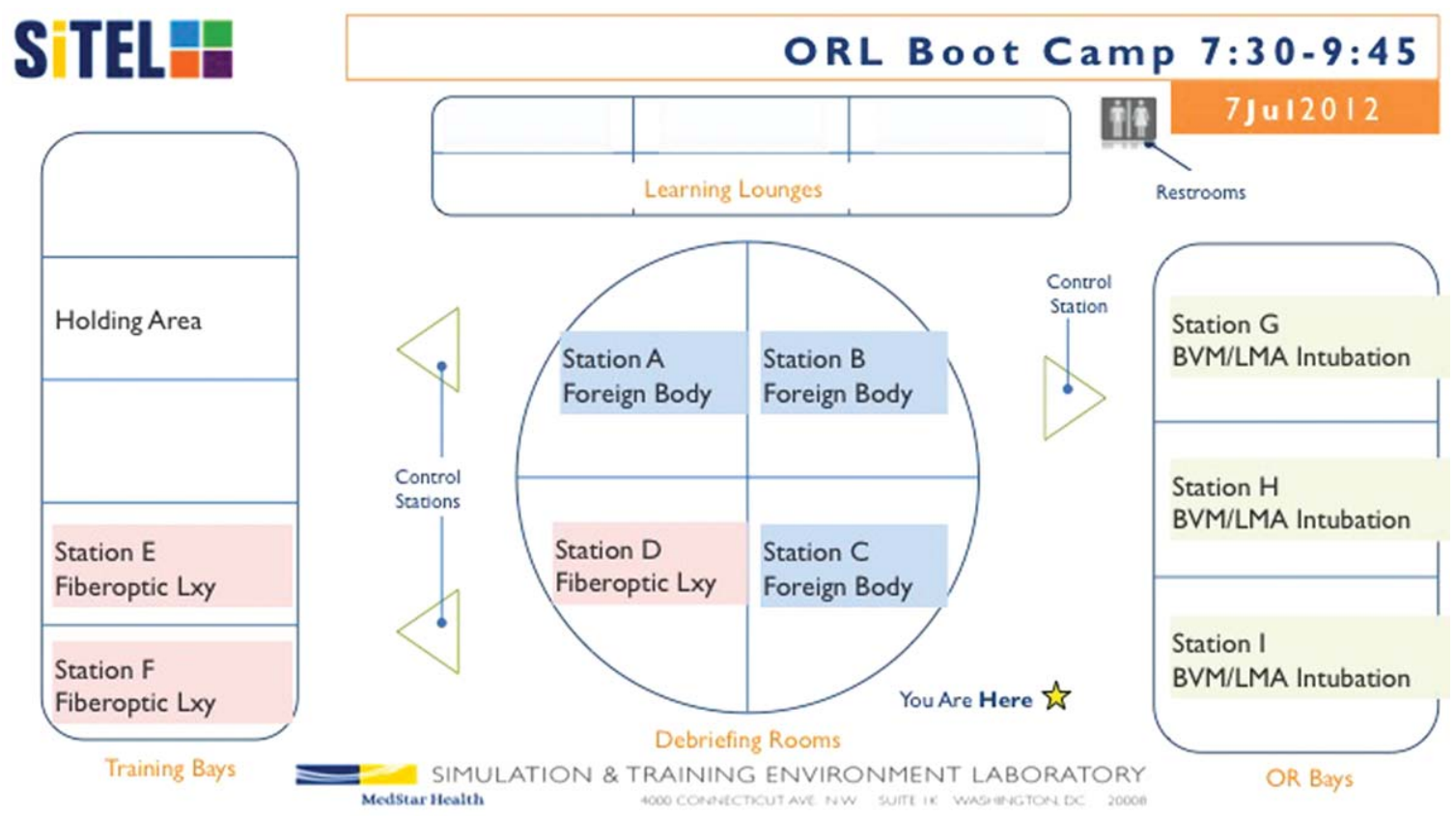

Fig. 1. Floor plan details demonstrating the first round of stations. This will differ based on space, available equipment, and number of learners, but it shows how multiple groups can work at multiple stations simultaneously. BVM = bag valve mask; LMA = laryngeal mask airway; Lxy = laryngoscopy; ORL = otorhinolaryngology. 
learning objectives, basic information addressing the indications and the performance of the procedure, equipment needs, and clinical pearls.

\section{Basic Airway Skills}

Mask ventilation, intubation, insertion of oropharyngeal airways, nasopharyngeal airways, and laryngeal mask airways (LMAs) are basic airway skills, which should be in the armamentarium of otolaryngology residents (see Handouts, Supplementary Information 2 and 3). Many of these methods may be used to temporize airway management until additional assistance is available and potentially to avoid the need for more invasive airway management procedures.

We use a variety of simulators, representing infant, pediatric, and adult airways so that residents can select age-appropriate equipment and supplies (Fig. 2). Both task-trainers and high-technology manikins can be used; high-technology manikins are used in passive mode to simplify the exercise (except that the electronic controls for the Pediatric HAL manikin [S3005; Gaumard, Miami, FL] must be turned on to allow ventilation). We test the manikins for suitability for various devices, so that a correctly inserted device will function properly. For example, in some models, mask ventilation can be accomplished even if an appropriate mask seal has not been obtained; therefore, a resident may learn poor technique. In other models, even if an LMA is inserted correctly, ventilation and chest rise will not occur, so a resident does not get the appropriate feedback even if a skill is performed correctly. We have found that different models have different capabilities, and there is not one single model that is best for all skills. A list of the suggested skills to be practiced with several models is pro- vided in Supplementary Information 4. These suggestions are not rigid; faculty have the option to use whatever airway devices they select for each of the models. Task trainers and manikins are placed on tables or beds; the remaining equipment is placed on a table nearby. Each of the devices is tested to ensure that they are appropriately sized and functional. Additional equipment and supplies are listed in Supplementary Information 5.

\section{Fiberoptic Laryngoscopy and Intubation}

Fiberoptic nasopharyngoscopy and laryngoscopy are basic skills that residents will need to master and perform in a variety of locations and settings (see Handout, Supplementary Information 6). Although fiberoptic laryngoscopy can be performed at bedside with a selfcontained viewing system, it is helpful in this learning situation to use a monitor that can be viewed by the faculty simultaneously with the learner.

An assortment of infant, child, and adult intubation task trainers or full-body manikins are used. Examine the manikins to determine which have the best anatomic fidelity. Position the manikins so that fiberoptic endoscopy can be performed in several realistic positions, with the manikin lying supine on a bed (or table) and the examiner standing at the manikin's head and also by the manikin's side, and with the manikin sitting in a chair facing the examiner (Fig. 3). Test the task trainers and manikins to determine the optimal endotracheal tube sizes and to determine whether fiberoptic laryngoscopy can be performed as the manikin is positioned (in some cases, excess tissue in the nasopharynx, or neck flexion resulting from upright positioning, interferes with progression of the fiberoptic telescope). Equipment and supplies are listed in Supplementary Information 7.

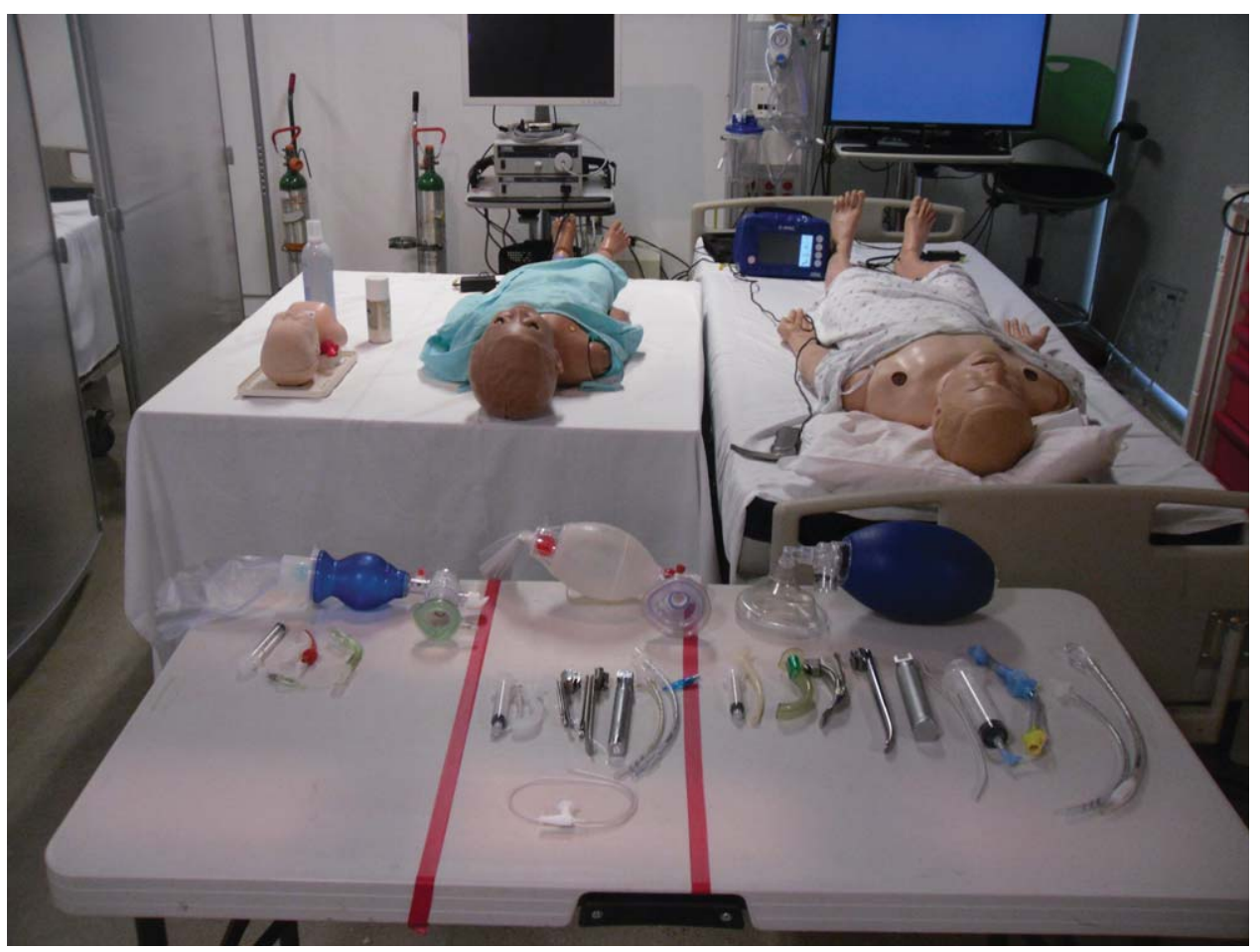

Fig. 2. Equipment and manikins used for basic airway skills station. 
Fig. 3. Setup with manikins and equipment for fiberoptic laryngoscopy station.

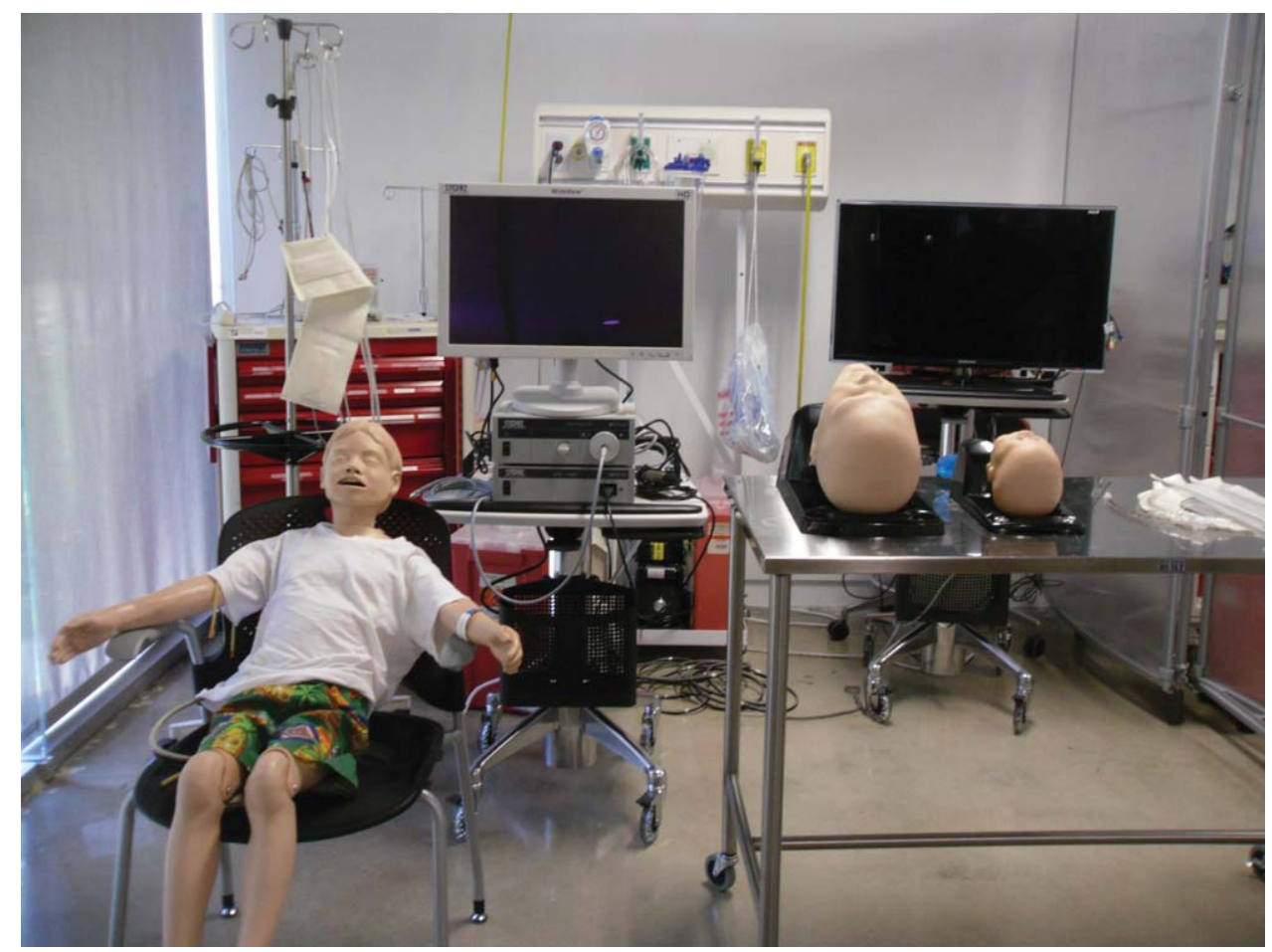

These stations describe the foundation skills taught in the ORL Emergencies Boot Camp; they provide the basis upon which more specialized and advanced skills and patient management scenarios are built. This will be further explored in subsequent articles: SimulationBased Otorhinolaryngology Emergencies Boot Camp Part 2 will address complex skills, and Part 3 will describe teamwork scenarios and discuss conclusions regarding boot camp curricula.

\section{Acknowledgments}

The boot camps are successful because of the skill of the simulation center staff, and the invaluable enthusiasm and generosity of our volunteer faculty. The following faculty have contributed their time and their expertise: Oneida Arosarena, MD; Joshua Bedwell, MD; Elizabeth Blair, MD; Scott Brietzke, MD; David Brown, MD; Houtan Chaboki, MD; Joshua Bedwell, MD; Kristi Chang, MD; Stan Chia, MD; Sukgi Choi, MD; Bruce Davidson, MD; David Eibling, MD; Kevin Fung, MD; Nazaneen Grant, MD; Hosai Hesham, MD; Earl Harley, MD; Stacey Ishman, MD; Jim Kearney, MD; Deidre Larrier, MD; Gi Soo Lee, MD; Johnathan McGinn, MD; Ben Malkin, MD; Greg Milmoe, MD; Ken Newkirk, MD; Karen Pitman, MD; Liana Puscas, MD; Michael Reilly, MD; James Reilly, MD; Evan Reiter, MD; Margaret Skinner, MD; Scott Schoem, MD;
Merry Sebelik, MD; Rahul Shah, MD; Rose Mary Stocks, MD; Wasyl Szeremeta, MD; Marc Thorne, MD; Mark Volk, MD; Jeff Wolf, MD; Phil Zapanta, MD.

\section{BIBLIOGRAPHY}

1. Malekzadeh S, Malloy KM, Chu EE, Tompkins J, Battista A, Deutsch ES. ORL emergencies boot camp: Using simulation to onboard residents. Laryngoscope 2011;121:2114-2121.

2. Deutsch ES, Orioles A, Kreicher K, Malloy KM, Rodgers DL. A qualitative analysis of faculty motivation to participate in otolaryngology simulation boot camps. Laryngoscope 2013;123:890-897.

3. Nishisaki A, Hales R, Biagas K, et al. A multi-institutional high-fidelity simulation "boot camp" orientation and training program for first year pediatric critical care fellows. Pediatr Crit Care Med 2009;10: 157-162.

4. Pliego JF, Wehbe-Janek H, Rajab MH, Browning JL, Fothergill RE. OB/ GYN boot cAMP using high-fidelity human simulators: enhancing residents' perceived competency, confidence in taking a leadership role, and stress hardiness. Simul Healthc 2008;3:82-89.

5. Fann JI, Calhoon JH, Carpenter AJ, et al. Simulation in coronary artery anastomosis early in cardiothoracic surgical residency training: the boot camp experience. $J$ Thorac Cardiovasc Surg 2010;139:1275-1281.

6. Sonnadara RR, Van Vliet A, Safir O, et al. Orthopedic boot camp: examining the effectiveness of an intensive surgical skills course. Surgery 2011; 149:745-749.

7. Selden NR, Barbaro N, Origitano TC, Burchiel KJ. Fundamental skills for entering neurosurgery residents: report of a pacific region "boot camp" pilot course, 2009. Neurosurgery 2011:68:759-764.

8. Dehmer JJ, Stafford RE, Marshall HP, Koruda MJ, Meyer AA. Boot camp: a method of introducing the competency of professionalism to surgical residents. Am Surg 2011;77:960-961.

9. Ferguson CM. Effects of a surgical skills boot camp. J Am Coll Surg 2010; 211:691-692. 